\title{
ACL Surgical Technique - Staying Out of Trouble
}

\author{
Vlad Predescu', Radu Prejbeanu², Robert Bordea², Adrian Todor ${ }^{3}$, Bogdan Codorean, Mihai \\ Roman4, Radu Fleaca ${ }^{4}$, Octav Russu ${ }^{5}$, Tiberiu Bățagă5 ${ }^{5}$ Bogdan Deleanu² \\ 1 "Carol Davila" University of Medicine and Pharmacy, Bucharest, Romania \\ 2 "Victor Babeș" University of Medicine and Pharmacy, Timișoara, Romania \\ 3 "Iuliu Hațieganu" University of Medicine and Pharmacy Cluj-Napoca, Romania \\ 4 "Victor Papillan" Faculty of Medicine, "Lucian Blaga” University, Sibiu, Romania \\ 5 University of Medicine and Pharmacy, Tîrgu Mureș, Romania
}

\section{CORRESPONDENCE}

\section{Robert Bordea}

P-ța Eftimie Murgu nr. 2 300041 Timișoara, Romania

Tel: +40 256204400

E-mail: bordea.robert@yahoo.com
Vlad Predescu • B-dul Eroii Sanitari nr. 8, 050474 București, Romania. Tel: +40 213180 719, E-mail: vladpredescu001@gmail.com

Radu Prejbeanu • P-ța Eftimie Murgu nr. 2, 300041 Timișoara, Romania. Tel: +40 256204 400, E-mail: raduprejbeanu@gmail.com

Adrian Todor • Str. Emil Isac nr. 13, 400023 ClujNapoca, Romania. Tel: +40 264406 843, E-mail: adi. todor@yahoo.com

Bogdan Codorean • B-dul Eroii Sanitari nr. 8, 050474 București, Romania. Tel: +40 213180 719, E-mail: dr.codorean@traumatologie-sportiva.ro

Mihai Roman • Str. Lucian Blaga nr. 2A, 550169 Sibiu, Romania. Tel: +40 269212 320, E-mail: mihaidanroman@yahoo.com

Radu Fleaca • Str. Lucian Blaga nr. 2A, 550169 Sibiu, Romania. Tel: +40 269212 320, E-mail: rfleaca@ yahoo.com

Octav Russu • Str. Gheorghe Marinescu nr. 38 , 540139 Tîrgu Mureș, Romania. Tel: +40 265215 551, E-mail: octav@genunchi.ro

Tiberiu Bățagă • Str. Gheorghe Marinescu nr. 38 540139 Tîrgu Mureș, Romania. Tel: +40 265215551 , E-mail: tbataga@gmail.com

Bogdan Deleanu • P-ța Eftimie Murgu nr. 2, 300041 Timișoara, Romania. Tel: +40 256204 400, E-mail: bogdandeleanu@yahoo.com

\begin{abstract}
The incidence of $A C L$ tear and reconstruction has increased over time, and failure of $A C L$ reconstruction is not perfectly defined among surgeons. Atraumatic failure of $A C L$ surgery represents approximately $70 \%$ of causes, and occurs in diagnostic errors, technical errors and problems of $\mathrm{ACL}$ graft integrations. Regarding surgical technique, we should answer certain questions about our choice of surgery, tunnel position, graft type, graft suture, tensioning the graft, and how we deal with certain incidents or intraoperative accidents. The purpose of this article is to review the current information and trends of $A C L$ reconstruction, and presents some tips and tricks we use in our current practice.
\end{abstract}

Keywords: anterior cruciate ligament (ACL), reconstruction, technique, tips, anterolateral ligament (ALL)

\section{INTRODUCTION}

The overall rate of ACL tears is not well documented, but different studies in the United States of America have reported 100,000 to 200,000 ACL tears every year. ${ }^{1-4}$ The prevalence of ACL tears is increasing around the globe every year, and due to sports activities, the female-male ratio of ACL tear incidence and reconstruction has increased over time. ${ }^{5-7}$ Over 100,000 ACL reconstructions are reported in the USA every year, and between 10 and $15 \%$ are revisions. ${ }^{8,9}$

The failure of ACL reconstruction is not perfectly defined among surgeons. Classically, there are traumatic and atraumatic causes of failed ACL reconstructions in the literature. Atraumatic failure of ACL surgery represents approximately $70 \%$ of causes, and occurs in diagnostic errors, technical errors and problems of ACL graft integrations. ${ }^{10,11}$ 
There are differences between clinical examination and KT measurements regarding the diagnosis of an ACL graft rupture or ACL surgery failure, and around $0.7-10 \%$ of recurrent instability 5 years post-ligamentoplasty. ${ }^{12}$

\section{PROBLEMS TO SOLVE}

Obtaining knee stability and rapid return to previous level of sports activities are short-term goals regarding ACL surgery.

Preventing arthritic changes and minimizing cartilage wear are long-term problems to solve. Regarding these goals of ACL reconstructive surgery, we should look back and evaluate if we succeeded in terms of benefit.

\section{STILL A CHALLENGE - WHY?}

Surgical errors are the most frequent cause of graft failure (around 70\%). ${ }^{11-13}$

Graft integration is the factor that ultimately demonstrates the success of surgical intervention. A rapid and strong integration of the graft allows early rehabilitation and recovery of the knee. A series of biologic strategies of promoting intraarticular and intraosseous healing by use of cytokines, stem cells and gene therapy are currently under investigation, and will be clinically important in the near future. ${ }^{14,15}$

Sepsis leading to ACL failure and graft integration problems is rare (up to $1 \%$ ), but it is a demanding medical problem requiring antibiotics and arthroscopic reinterventions. ${ }^{16}$

Trauma can cause excessive tension upon the newly reconstructed ACL in the early postoperative period due to aggressive rehabilitation before the healing process and graft integration had been completed. Repetitive trauma in athletes may lead to failure in graft integration or rerupture of the new ACL.

Patient selection is important in terms of compliance to postoperative movement restrictions, rehabilitation protocol and return to sport activity. As for the indications of surgical treatment, we should focus more on the activity level of the patient prior to surgery, and less on the patient's age.

Surgical timing can affect the clinical outcome, but in the literature there is no consensus regarding the right timing of ACL surgery. In certain studies the authors have found that if surgery is done within the first week following the trauma, there is a great risk of developing arthrofibrosis, however, newer studies correlate the risk of developing arthrofibrosis with the muscular and functional status of the knee prior to the trauma, more than with the injury-to-surgery interval. ${ }^{17,18}$

There are studies that found that quadriceps strength deficits prior to surgery are correlated with the clinical outcome, and suggested that ACL surgery should be performed when the involved quadriceps muscle strength is at least $80 \%$ of the contralateral lower extremity. ${ }^{19}$

Acute ACL reconstruction may be an option for professional athletes who must return to sport as soon as possible. $^{20}$

A successful surgical intervention is one that uses a solid thick graft that is placed anatomically, and is fixed with a solid device.

Regarding surgical technique, we should answer certain questions about our choice of surgery, tunnel position, graft type, graft suture, tensioning the graft, and how we deal with certain incidents or intraoperative accidents.

In the 1980s, ACL reconstruction was using the 2-incision technique, and in the 1990s it was using one transtibial arthroscopic incision that provided a vertically positioned ACL graft. It was demonstrated that the latter technique resisted to anterior tibial translation, but often it was not capable of resisting to internal tibial rotation. ${ }^{21-23}$

Over time, the technique of ACL reconstruction shifted from isometric toward anatomical, and from single-bundle toward double-bundle. Recent studies reported superior results of anterior and rotational stability using the double-bundle technique, but no subjective clinical differences were found between the double or single anatomical bundle technique groups. ${ }^{24-26}$

Currently, we have two alternatives to consider - the anatomic single-bundle medial portal, or all-inside technique, and the anatomic double-bundle. New trends in ACL surgery gravitate toward the anatomic single-bundle with anterolateral ligament reconstruction.

\section{TIPS AND TRICKS}

\section{Tip no. 1 - Antero-medial portal}

Low medial portal (extend medially, just off the medial femoral condyle), make a longitudinal tegument incision, resect some of the fat pad, identify the femoral start point with the knee in a $90^{\circ}$ angle flexion, almost in the center of the ACL footprint, drill the guide wire with the knee flexed at $120^{\circ}$, and pay attention to press-fit fixation.

\section{Tip no. 2 - Notchplasty}

Many authors perform notchplasty, but several studies reveal that it poses a stress on the graft, and it represents 
a risk for a possible future failure of the reconstructed ACL.27,28 Some studies reveal arthroscopic and MRI modifications of the femoral notch, namely fibrocartilage and bone ingrowth that lead to late impingement failure of surgery.29,30 In conclusion, the use of routine notchplasty remains controversial.

\section{Tip no. 3 - Identify the femoral footprint}

By use of a second medial portal the surgeon must identify anatomical structures like the medial lateral femoral condyle, intercondylar ridge, bifurcate ridge, crescent footprint $(18 \mathrm{~mm} / 11 \mathrm{~mm})$, the middle of the footprint (measurements with ruler) at $40-50 \%$ from the measured anteroposterior distance, close to the cartilage in the distal part (final tunnel 2-3 mm from the cartilage). No clock position is used.

\section{Tip no. 4 - Drilling a femoral socket}

With the knee flexed at $120^{\circ}$, by use of the low medial portal we have to drill a guide wire, measuring the length of the condyle (around $35 \mathrm{~mm}$ ). The socket will be shallow (press fit or all-inside). We must drill a tunnel with a diameter $0.5 \mathrm{~mm}$ smaller than the graft diameter, and be careful with the cartilage of the medial femoral condyle. The bone debris from the tunnel is to be removed, and the tunnel length must be at least $20 \mathrm{~mm}$ long.

\section{Tip no. 5 - Graft preparation}

The graft should be as thick as possible to cover the footprint. Do not accept soft tissue less than $8 \mathrm{~mm}$ (if possible). The graft should not be too long if it is a suspension fixation (elastic/hybrid). We must measure the graft in tension, and remember to press fit (biologic integration/tunnel enlargement).

\section{Tip no. 6 - Tibial tunnel}

The tibial tunnel must be drilled in the middle of the tibial footprint or at the junction of the medial and middle third (depending on the graft diameter), measured with the ruler at a $70^{\circ}$ flexion of the knee. The guide wire must be in line with the posterior margin of the anterior horn of the lateral meniscus - more anterior than it was in the past (30-40\% in sagittal plane). We should leave the residual ACL stump for the benefit of integration, proprioception and tunnel enlargement. The tunnel length is $35-45 \mathrm{~mm}$.

\section{Tip no. 7 - Final tuning}

We must check the final position in extension for impingement. We must drill (sequentially) $4.5 \mathrm{~mm}$, and then reposition the guide wire 1-2 mm if needed. We should not perforate the ACL stump (if possible), and try to keep the ACL stump. Graft fixation must be solid, and the surgeon must be familiar with its use. Our personal experience concerns a tight rope and a peek screw on the tibia, and we drill $1 \mathrm{~mm}$ more than the tunnel diameter for men and 2 $\mathrm{mm}$ more than the tunnel diameter for women.

\section{Tip no. 8 - Graft tensioning}

We should not put too much tension on the graft, since graft necrosis may appear. A 4-6 kg tension is recommended, with flexion of the knee around $20^{\circ}$ and posterior drawer.

Errors related with ACL reconstruction surgery include tunnel malpositioning, wrong graft choice or preparation, isometric graft (error or not?), fixation failure, graft failure, and associated ligament tears.

In the literature, authors describe residual pivot-shift despite a good reconstruction of the ACL, which is correlated with poor patient satisfaction. ${ }^{31}$

One recent technique is the "all-inside" technique, which is a "no-tunnel technique" that has the potential advantage of minimizing morbidity, creating closed tunnels ("blind sockets"). This technique uses a cannulated retrograde drill or "flip cutter" (Arthrex), and has the flexibility of graft choice, fixation, single-/double-bundle. Another advantage is improved cosmetics (no tibial drilling), and less bleeding and pain. This technique uses a "graft link" suture technique of a quadrupled ST graft or allograft of approximately $75-80 \mathrm{~mm}$ graft length, a retrograde drill and Passport silicone cannula on the AM portal. ${ }^{32,33}$

In the literature, there are studies that mention residual rotational instability after ACL reconstruction, and also studies about anterolateral ligament role in rotational stability. ${ }^{34-36}$ All these information raise new questions about the need of lateral reinforcement in anterior ligament reconstruction.

The anterolateral ligament (ALL) was first described in 1879 by the French surgeon Paul Segond, who described a fibrous band between the lateral femur and the tibia that he had observed during studies of tibial eminence fractures. ${ }^{37}$

Recent cadaver studies identified the origin of the ALL at the lateral femoral epicondyle, slightly anterior to the origin of the lateral collateral ligament, the oblique course toward its insertion on the anterolateral tibia, which is located midway between the tip of the fibular head and Gerdy's tubercle, and the authors found no connection with the iliotibial band. . $^{37,38}$

A recent study reviewed 92 patients with ALL reconstruction associated with ACL, and reported very promising results with a significant decrease in anterior and rotational instability. ${ }^{39}$ 
We should not forget that complex ligament injuries, such as posterior cruciate tear, posterolateral corner lesion, medial collateral ligament tear or residual laxity, affect the result of ACL surgery leading to failure..$^{40}$

After ACL reconstruction we suggest returning to sport after a minimum of 6 months, when the knee has no swelling, the range of motion is 0 to $150^{\circ}$, when the full sprinting program is completed, quadriceps strength is at least $85 \%$ compared to the contralateral limb, hamstrings strength is at least $90 \%$ of the contralateral limb, and the Hoop test is minimum $85 \%$.

\section{CONCLUSION}

The first step toward better results in ACL surgery is understanding ACL anatomy and identifying the footprint. The second step is to be aware of the technical demands and realizing that it is a technique with a lot of complications, one that requires a good fixation of an optimally prepared graft. And finally, we should remember that choosing the right patient for surgery and keeping close observation of this patient during the recovery period is not the least important factor of excellent results of ACL surgery.

\section{REFERENCES}

1. Griffin LY, Albohm MJ, Arendt EA, et al. Understanding and preventing noncontact anterior cruciate ligament injuries: a review of the Hunt Valley II meeting, January 2005. Am J Sports Med. 2006;34:1512-1532.

2. Mall NA, Chalmers PN, Moric M, et al. Incidence and trends of anterior cruciate ligament reconstruction in the United States. Am J Sports Med. 2014; $42: 2363-2370$.

3. Gordon MD, Steiner ME. Anterior cruciate ligament injuries. In: Orthopaedic Knowledge Update Sports Medicine III, Garrick JG. (Ed), American Academy of Orthopaedic Surgeons, Rosemont 2004. p. 169.

4. Albright JC, Carpenter JE, Graf BK, et al. Knee and leg: soft tissue trauma. In: Orthopaedic Knowledge Update 6, Beaty JH. (Ed), American Academy of Orthopaedic Surgeons, Rosemont 1999. p. 533.

5. Waldén M, Hägglund M, Werner J, Ekstrand J. The epidemiology of anterior cruciate ligament injury in football (soccer): a review of the literature from a gender-related perspective. Knee Surg Sports Traumatol Arthrosc. 2011;19:3-10.

6. Hewett TE. Neuromuscular and hormonal factors associated with knee injuries in female. Strategies for intervention. Sports Med. 2000;29:313327.

7. Prodromos CC, Han Y, Rogowski J, Joyce B, Shi K. A meta-analysis of the incidence of anterior cruciate ligament tears as a function of gender, sport, and a knee injury-reduction regimen. Arthroscopy. 2007;23:1320-1325.e6.

8. Buller LT, Best MJ, Baraga MG, Kaplan LD. Trends in Anterior Cruciate Ligament Reconstruction in the United States. Orthop J Sports Med. 2014;3(1):2325967114563664

9. Samitier G, Marcano Al, Alentorn-Geli E, Cugat R, Farmer KW, Moser MW. Failure of Anterior Cruciate Ligament Reconstruction. Arch Bone JT Surg. 2015:3:220-240.

10. MARS Group, Wright RW, Huston LJ, et al: Descriptive epidemiology of the Multicenter ACL Revision Study (MARS) cohort. Am J Sports Med. 2010;38:1979-1986.

11. George MS, Dunn WR, Spindler KP. Current concepts review: revision anterior cruciate ligament reconstruction. Am J Sports Med. 2006;34:2026-2037
12. Alford JW, Bach BR. Arthrometric aspects of anterior cruciate ligament surgery before and after reconstruction with patellar tendon grafts. Techniques in Orthopaedics. 2005;20:421-438.

13. Bach BR. Revision ACL reconstruction: indications and technique. In: Miller MD, Cole BJ, editors. Textbook of Arthroscopy. Philadelphia: Elsevier, 2004. p. 896

14. Tomita F, Yasuda K, Mikami S, Sakai T, Yamazaki S, Tohyama H. Comparisons of intraosseous graft healing between the doubled flexor tendon graft and the bone-patellar tendon-bone graft in anterior cruciate ligament reconstruction. Arthroscopy. 2001;17:461-476.

15. Chih-Hwa C. Graft healing in anterior cruciate ligament reconstruction. Sports Med Arthrosc Rehabil Ther Technol. 2009;1:21.

16. Burks RT, Friederichs MG, Fink B, et al. Treatment of Postoperative Anterior Cruciate Ligament Infections with Graft Removal and Early Reimplantation. Am J Sports Med. 2003;31:414-418.

17. Shelbourne KD, Wilckens JH, Mollabashy A, DeCarlo M. Arthrofibrosis in acute anterior cruciate ligament reconstruction. The effect of timing of reconstruction and rehabilitation. Am J Sports Med. 1991;19:332-336.

18. Mayr HO, Weig TG, Plitz W. Arthrofibrosis following ACL reconstruction - reasons and outcome. Arch Orthop Trauma Surg. 2004;124:518-522.

19. Eitzen I, Holm I, Risberg MA. Preoperative quadriceps strength is a significant predictor of knee function two years after anterior cruciate ligament reconstruction. Br J Sports Med. 2009;43:371-376.

20. Evans S, Shaginaw J, Bartolozzi A. ACL Reconstruction - It's all about timing. Int J Sports Phys Ther. 2014;9:268-273.

21. Kato $Y$, Ingham SJ, Kramer S, Smolinski P, Saito A, Fu FH. Effect of tunnel position for anatomic single-bundle $A C L$ reconstruction on knee biomechanics in a porcine model. Knee Surg Sports Traumatol Arthrosc. 2010;18:2-10.

22. Loh JC, Fukuda Y, Tsuda E, Steadman RJ, Fu FH, Woo SL. Knee stability and graft function following anterior cruciate ligament reconstruction: comparison between the 11 o'clock and 10 o'clock femoral tunnel placement. 2002 Richard O'Connor Award paper. Arthroscopy. 2003;19:297-304

23. Yamamoto Y, Hsu WH, Woo SL, Van Scyoc A, Takakura Y, Debski RE. Knee stability and graft function after anterior cruciate ligament reconstruction: a comparison of a lateral and an anatomical femoral tunnel placement. Am J Sports Med. 2004; 32:1825-1832.

24. Meredick RB, Vance KJ, Appleby D, Lubowitz JH. Outcome of singlebundle versus double-bundle reconstruction of the anterior cruciate ligament: a meta-analysis. Am J Sports Med. 2008;36:1414-1421.

25. Kawaguchi $Y$, Kondo E, Kitamura N, et al. Comparisons of femoral tunnel enlargement in 169 patients between single-bundle and anatomic doublebundle anterior cruciate ligament reconstructions with hamstring tendon grafts. Knee Surg Sports Traumatol Arthrosc. 2011;19:1249-1257.

26. Jarvela T. Double-bundle versus single-bundle anterior cruciate ligament reconstruction: a prospective, randomize clinical study. Knee Surg Sports Traumatol Arthrosc. 2007;15:500-507.

27. Markolf KI, Hame SL, Hunter DM, Oakes D, Gause P. Biomechanical effects of femoral notchplasty in anterior cruciate ligament reconstruction. Am J Sports Med. 2002;30:83-89.

28. Keklikci K, Yapici C, Kim D, Fu F. The effect of notchplasty in anterior cruciate ligament reconstruction: a biomechanical study in the porcine knee. Knee Surg Sports Traumatol Arthrosc. 2013;21:1915-1921.

29. Watanabe BM, Howell SM. Arthroscopic findings associated with roof impingement of an anterior cruciate ligament graft. Am J Sports Med. 1995;23:616-625

30. David AM, Wiliam NS, Robert B, Ronald J. MRI Findings in Anterior Cruciate Ligament Reconstruction: Evaluation of Notchplasty. AJR Am J Roentgenol. 1997;169:217-222.

31. Kocher MS, Steadman JR, Briggs K, Zurakowski D, Sterett WI, Hawkins RJ. Determinants of patient satisfaction with outcome after anterior cruciate ligament reconstruction. J Bone Joint Surg Am. 2002;84-A:1560-1572.

32. Potalivo G, Placella G, Sebastiani E. History of the "All Inside Technique" and its Clinical Application. Journal of Orthopedics. 2011;3:81-86

33. Wilson AJ, Yasen SK, Nancoo T, Stannard R, Smith JO, Logan JS Anatomic All-Inside Anterior Cruciate Ligament Reconstruction Using the Translateral Technique. Arthrosc Tech. 2013;2:e99-e104.

34. Caterine S, Litchfield R, Johnson M, et al. A cadaveric study of the anterolateral ligament: re-introducing the lateral capsular ligament. Knee Surg Sports Traumatol Arthrosc. 2015;23:3186-3195.

35. Monaco E, Ferretti A, Labianca L, et al. Navigated knee kinematics after cutting of the ACL and its secondary restraint. Knee Surg Sports Traumatol Arthrosc. 2012;20:870-877. 
36. Spencer L, Burkhart TA, Tran MN, et al. Biomechanical analysis of simulated clinical testing and reconstruction of the anterolateral ligament of the knee. Am J Sports Med. 2015;43:2189-2197.

37. Claes S, Vereecke E, Maes M, Victor J, Verdonk P, Bellemans J. Anatomy of the anterolateral ligament of the knee. J Anat. 2013;223:321-328.

38. Vincent JP, Magnussen RA, Gezmez F, et al.The anterolateral ligament of the human knee: an anatomic and histologic study. Knee Surg Sports Traumatol Arthrosc. 2011;20:147-152.
39. Sonnery-Cottet B, Thaunat M, Freychet B, et al. Outcome of a Combined Anterior Cruciate Ligament and Anterolateral Ligament Reconstruction Technique With a Minimum 2-Year Follow-up. Am J Sports Med. 2015;43:1598-1605.

40. Clancy W, Pietropaoli M. Revision Anterior Cruciate Ligament Reconstruction Using the "Anatomic-Endoscopic" Method. Techniques in Orthopaedic. 1998;13:391-410. 